\title{
Studies on Antibiotics Produced at High Alkaline pH
}

\author{
Michikatsu Sato, ${ }^{*}$ Teruhiko BePPU and Kei Arima \\ Department of Agricultural Chemistry, \\ The University of Tokyo, Tokyo 113, Japan
}

Received February 1, 1983

\begin{abstract}
Screening by using high alkaline media was carried out to detect new antibiotics produced by alkalophilic and alkali-resistant microorganisms. Three thousand strains of microorganisms, mainly fungi and streptomycetes, were isolated on high alkaline media ( $\mathrm{pH}$ 10.3). The microorganisms consisted of 1206 strains of streptomycetes, 1511 strains of fungi and 283 strains of bacteria. Among these strains, 151 strains of streptomycetes, 148 strains of fungi and 36 strains of bacteria showed antimicrobial activities. One strain of alkalophilic streptomycetes, Streptomyces sp. No. 1543, produced antimycin A. An alkali-resistant fungi, strain No. 401, identified as Verticillium lecanii, produced helvolic acid. An alkalophilic fungi, strain No. 1907, identified as Paecilomyces lilacinus, produced a group of homologous new peptide antibiotics, Nos. 1907-II to VIII, in a broth fermented under the high alkaline conditions.
\end{abstract}

Since more than 5000 antibiotics have already been found to date, there may be increasing difficulty in discovering new antibiotics under normal cultural conditions. Screening of antibiotics by using an extreme cultural condition is one possible way to overcome this difficulty, and several successful examples have already been reported, such as, pyrrolnitrin $^{11}$ and other antibiotics newly produced by using high phosphate containing media; cryomycin ${ }^{2)}$ and another new antibiotic produced by psychrophiles at low temperature; SS- $228^{3)}$ produced by marine microorganisms of the genus Chainia in media containing Kobu-Cha (powdered tangle sea weed; Laminaria); and also aplasmomycin ${ }^{4)}$ produced by marine streptomycetes in media of high sodium chloride concentration. We chose high alkaline media as an extreme condition for isolation of microorganisms producing new antibiotics. Although Horikoshi et al. have found many new enzymes ${ }^{5,6}$ produced by alkalophilic bacteria using high alkaline media, there have been no reports on any antibiotics produced by alkalophilic or alkalineresistant streptomycetes and fungi known to be important antibiotic producers. Our screen- ing revealed that several microorganisms produced potent antibiotics under the alkaline conditions. A strain of alkalophilic fungus was found to produce a novel antifungal peptide antibiotic, No. 1907-II, and its homologues. Its chemical structure and antimicrobial activities were reported previouly. ${ }^{7)}$

This paper deals with fermentation and purification of antibiotics of the strain No. 1907 and taxonomical studies on the producing microorganism along with summarized results of the screening under high alkaline conditions.

\section{MATERIALS AND METHODS}

Isolation of microorganisms grown on high alkaline media. A small amount of soil was suspended in sterilized water and spread on a plate containing high alkaline medium. Medium A and Medium B were used as the isolation media and the compositions are shown in Table I. The plates were incubated at $26.5^{\circ} \mathrm{C}$ for 6 to 10 days. The colonies formed on a plate were transferred to slants containing Medium A, and incubated at $26.5^{\circ} \mathrm{C}$ for 7 to 10 days.

Cultivation of strains for screening of new antibiotics. For detecting antibiotic formation, one loopful of an organism grown on an agar slant was inoculated into $10 \mathrm{ml}$ of liquid

* Present address: Central Research Laboratories, Sanraku-Ocean Co., Ltd., 1-9, Johnan, Fujisawa 251, Japan. 
TABLE I. Composition of MediA

\begin{tabular}{lcccc}
\hline \multicolumn{1}{c}{$\begin{array}{c}\text { Components } \\
\text { (g/liter) }\end{array}$} & \multicolumn{5}{c}{ Medium } \\
\cline { 2 - 5 } & A & B & $\mathrm{C}$ & $\mathrm{D}$ \\
\hline Glucose & 10 & 10 & 5 & 5 \\
Soluble starch & - & - & 30 & 30 \\
Malt extract & - & - & - & 10 \\
Soy bean meal & - & - & 15 & - \\
L-Asparagine & - & 0.3 & - & - \\
Peptone & 5 & 0.2 & 3 & - \\
Yeast extract & 5 & 0.1 & - & 1 \\
Dried yeast & - & - & 2 & - \\
$\mathrm{K}_{2} \mathrm{HPO}_{4}$ & 1 & 1 & 1 & 1 \\
$\mathrm{NaCl}$ & - & - & 1 & - \\
$\mathrm{MgSO}_{4} \cdot 7 \mathrm{H}_{2} \mathrm{O}$ & 0.2 & 0.1 & 0.5 & 0.5 \\
$\mathrm{Fe}_{2}\left(\mathrm{SO}_{4}\right)_{3} \cdot 6 \mathrm{H}_{2} \mathrm{O}$ & - & 0.01 & 0.01 & 0.01 \\
$\mathrm{CuSO}_{4} \cdot 5 \mathrm{H}_{2} \mathrm{O}$ & - & 0.001 & 0.001 & 0.001 \\
$\mathrm{ZnSO}_{4} \cdot \mathrm{H}_{2} \mathrm{O}$ & - & 0.001 & 0.001 & 0.001 \\
$\mathrm{MnSO}_{4} \cdot \mathrm{H}_{2} \mathrm{O}$ & - & 0.001 & 0.001 & 0.001 \\
$\mathrm{Na}_{2} \mathrm{CO}_{3}{ }^{*}$ & 10 & 10 & 10 & 2.5 \\
$\mathrm{Agar}^{\quad}$ & 10 & 15 & - & - \\
$\mathrm{pH}$ & 10.3 & 10.3 & 10.3 & 9.6 \\
\hline
\end{tabular}

* Sodium carbonate was sterilized separately and added to the medium.

medium (Medium C) in a large test tube $(20 \mathrm{~mm}$ in diameter). The composition of Medium $\mathrm{C}$ is given in Table I. The organism was cultured on a reciprocal shaker $(220 \mathrm{rpm})$ at $26.5^{\circ} \mathrm{C}$ for 5 to 8 days.

Assay of antimicrobial activities. To the cultured broth was added the same volume of acetone and the mixture centrifuged. The supernatant was assayed by the pulp-disk method on an agar plate which contained a basal layer and a seed layer. The organisms used for the assay of antimicrobial activities were as follows: Candida albicans IAM 4905, Aspergillus niger IAM 3008, Bacillus subtilis PCI 219, Staphylococcus aureus FDA 209P, Pseudomonas aeruginosa IFO 3080 and Escherichia coli IAM 1182. The media for the assay of antimicrobial activities were Sabouraud's agar for fungi and yeasts, and nutrient agar for bacteria.

Assay of antibiotics of strain No. 1907 in fermentation broth. The assay of No. 1907 on large scale fermentation was carried out by the pulp-disk assay using Bacillus subtilis PCI 219 as test organism and also by high performance liquid chromatography (HPLC). For the latter analysis a sample was extracted with ethyl acetate from $2 \mathrm{ml}$ of broth, evaporated to dryness, dissolved in $0.1 \mathrm{ml}$ of methanol and assayed by HPLC (Waters Associate, Type 244) with a $\mathrm{C}_{18} \mu$ Bondapak column $(4 \mathrm{~mm} \times 30 \mathrm{~cm})$ and reverse-phase separation was carried out using acetonitril$0.01 \mathrm{M} \mathrm{NH}_{4} \mathrm{OAc}$ buffer, $\mathrm{pH} 4(70: 30, \mathrm{v} / \mathrm{v})$, as the solvent (flow rate, $1 \mathrm{ml} / \mathrm{minute}$ ). Antibiotics of strain No. 1907 were detected with a UV detector at $254 \mathrm{~nm}$.

Measurement of growth. Growth of fungal strain No. 1907 was monitored by total nucleic acid (T-NA) content in the broth. T-NA was measured by the Schmidt, Thannhauser and Schneider method. ${ }^{8)}$

Thin-layer chromatography of antibiotics of strain No. 1907. Assay samples were spotted on a precoated silica gel thin-layer plate (Silica Gel $60 \mathrm{~F}_{254}$; E. Merck, Darmstadt) and developed with an appropriate solvent system.

Silica gel column chromatography. Silica gel (Wako gel C-200) was packed into a column $(7.0 \mathrm{~cm} \times 52 \mathrm{~cm})$ with a mixed solvent of benzene and methanol $(10: 1, \mathrm{v} / \mathrm{v})$. The column was eluted stepwise with a mixed solvent of benzene and methanol $(10: 1$ and $1:, \mathrm{v} / \mathrm{v})$ and methanol only.

Silica gel partition column chromatography. Seven hundred and fifty grams of silica gel (Wako gel C-200) and $450 \mathrm{ml}$ of a buffer ( $0.01 \mathrm{M} \mathrm{NH}_{4} \mathrm{OAc}$ buffer, $\left.\mathrm{pH} 4\right)$ were mixed well before column packing. The silica gel containing the buffer was packed into a column $(5.4 \mathrm{~cm} \times 66 \mathrm{~cm})$ with a mixed solvent of benzene and $n$-butanol $(3: 4, v / v)$ saturated with the buffer. The column bed was equilibrated with 1.0 liter of the solvent used for packing and eluted with the solvent after a sample was loaded on to the column.

Sephadex LH-20 column chromatography. For the final purification of antibiotics No. 1907, active fractions on the silica gel partition column chromatography were applied on to a column $(1.9 \mathrm{~cm} \times 100 \mathrm{~cm})$ packed with Sephadex LH-20. The column was eluted with methanol at a flow rate of $20 \mathrm{ml}$ per hour.

\section{RESULTS AND DISCUSSION}

\section{Preliminary screening of microorganisms grown} on the high alkaline medium

The growth of various strains selected from the culture collection of our laboratory on a high alkaline medium was examined preliminarily. Among 21 strains of actinomycetes tested on medium A ( $\mathrm{pH} \mathrm{10.3),} \mathrm{only} \mathrm{one} \mathrm{strain}$ of the genus Nocardia successfully grew on the medium. As for fungi, 15 strains could grow on the high alkaline medium among 20 tested strains of plant pathogenic fungi, but in other genera of fungi, e.g., Rhizopus, Mucor or Aspergillus, only small numbers of strains were found to grow on medium $\mathrm{A}$. The results are summarized in Table II. The low frequency of 
actinomycetes appearing on the high alkaline medium suggested that the screening might be effective for isolating rare strains of actinomycetes. Since $75 \%$ of plant pathogenic fungal strains could grow on the high alkaline medium, this cultivation method appears effective for isolating new plant pathogens from nature.

The number of microorganisms grown on a high alkaline medium were counted by using a soil sample from the Koishikawa Botanical Garden, Tokyo. It was estimated to be $10^{3} \sim 10^{5}$ per one gram of soil on medium A. On a neutral $\mathrm{pH}$ agar plate with sodium carbonate omitted from medium A, $10^{5} \sim 10^{7}$ colonies appeared in one gram of the same soil. Therefore, the number of colonies capable of growing on a high alkaline medium seemed to decrease by about $10^{-2}$ of that on a neutral $\mathrm{pH}$ medium. Among colonies on medium A, $60 \%$ of the colonies were bacteria, $30 \%$ were fungi and the remaining $10 \%$ were streptomycetes. As to the appearing colonies of streptomycetes the frequency increased to $25 \%$ on using medium B.

Screening of antibiotics produced by microorganisms isolated with high alkaline media

By using medium B we isolated 3000 microorganisms from 2500 soil samples. Numerous fungal colonies were isolated from botanical garden soils and many streptomycetes were isolated from farm soils. Among the 3000 microorganisms isolated, 1511 strains were fungi, 1206 strains were streptomycetes and the remaining 283 strains were bacteria. The strains having antimicrobial activities were 151 strains of streptomycetes, 148 strains of fungi and 36 strains of bacteria. Among the 148 strains of fungi 62 strains showed antifungal activities and 124 strains showed antibacterial activities. Among the 151 strains of streptomycetes 58 strains showed antifungal activities and 107 strains showed antibacterial activities. Among the 36 strains of bacteria 31 strains showed antibacterial activities and 5 strains showed antifungal activities. The detailed results are summarized in Table III. Antibiotics produced by bacterial strains were not further examined, because most of these substances were unstable and water soluble.

Secondary screening was carried out with the 151 strains of streptomycetes and 148 strains of fungi which were obtained in the primary screening. Antifungal activity with similar antimicrobial spectra against yeasts and fungi was shown by 15 strains of the alkalophilic streptomycetes, all of which seemed to belong to the genus Streptomyces judging from their morphological properties. One of them, strain No. 1543, showing good productivity of the antibiotic, was selected for further examination. The active principle was isolated and its physicochemical properties examined. The data were compared with those of known antibiotics and it was found to be identical with antimycin $\mathrm{A}^{9)}$ on comparison with an authentic sample. As there has been no report on the production of antimycin A by a strain of alkalophilic Streptomyces, the taxonomical properties of this strain, Streptomyces sp. No. 1543, will be reported separately.

One fungal strain, No. 401, produced an antibiotic which had potent antimicrobial activities against Gram positive cocci only. The antibiotic of No. 401 was identified as helvolic acid $^{10)}$ and the producing strain was identified as Verticillium lecanii. ${ }^{11)}$ Organisms in the genera Aspergillus, ${ }^{12)}$ Cephalosporium, ${ }^{13)}$ Emericellopsis $^{10)}$ and Streptomyces ${ }^{14)}$ are so far known as helvolic acid producers, and this is the first report of helvolic acid production by the genus Verticillium. Other reference culture of the genus Verticillium examined did not produce helvolic acid.

Another fungal strain, No. 1907, produced antibiotics which had broad and potent antimicrobial activities against bacteria, yeasts and fungi. Further examination of the properties of the active substances revealed their novel structures. $^{\text {7) }}$

\section{Isolation and identification of antimycin $A$} and helvolic acid from cultured broth

The cultured broth (1.0 liter) of strain No. 1543 was filtered and extracted with ethyl 


\section{Table II. Growth Testing of Stocked Cultures}

Medium A was used for both actinomycetes and fungi. Cultivation temperature was $26.5^{\circ} \mathrm{C}$. + , positive; - , negative.

Test organisms

Growth

$4 \quad 7 \quad 12$ (days)

Actinomycetes

Actinoplanes philipinensis IAM 0120

Micromonospora sp. Ru-3453

Nocardia asteroides NI 9038

Nocardia corallina ATCC 13259

Nocardia gardneri IAM 0105

Nocardia madurae NI 9108

Streptomyces albus IAM 0057

Streptomyces antibioticus NRRL B-546

Streptomyces coelicolor IFO 3176

Streptomyces flavovirens IAM 0117

Streptomyces fradiae IFO 3123

Streptomyces griseolus IAM 0021

Streptomyces hygroscopicus IAM 0118

Streptomyces olivaceus IFO 3260

Streptomyces phaeochromogenes IAM 0038

Streptomyces roseochromogenes IAM 0027

Streptomyces rubescens IAM 0074

Streptomyces salmonicida NRRL B-1472

Streptomyces vinaceus IAM 0042

Streptosporangium roseum IAM 0372

Fungi

Absidia hyalospora IAM 6188

Actinomucor repens IAM 6160

Aspergillus awamori IAM 2330

Aspergillus fumigatus IAM 2129

Aspergillus niger IAM 2093

Aspergillus oryzae IAM 2732

Chaetomium atrobrunneum IAM 8011

Echinodontium tsugicola IAM 9011

Monascus pilosus IAM 8003

Mucor circinelloides IAM 6080

Mucor javanicus IAM 6087

Mucor rouxii NI 1066

Penicillium chrysogenum IAM 7142

Penicillium notatum IAM 7168

Rhizopus chinensis IAM 6003

Phizopus delemar IAM 6020

Rhizopus japonicus IAM 6017

Trichophyton mentagrophytes IAM 5064

Plant pathogenic fungi

Alternaria brassicola A-7*

Botrytis tulipae IAM 5129

Cercospora beticola C-81*

Cephalosporium acremonium NI 4256

Cephalosporium mycophilum IAM 5026

Cladosporium fulvum IAM 5006

Colletotrichum glycines C-72*

Corticium centrifugum IAM 9028

\begin{tabular}{|c|c|c|}
\hline- & - & - \\
\hline- & - & - \\
\hline+ & + & + \\
\hline- & - & - \\
\hline- & - & - \\
\hline- & - & - \\
\hline- & - & - \\
\hline- & - & - \\
\hline- & - & - \\
\hline- & - & - \\
\hline- & - & - \\
\hline- & - & - \\
\hline- & - & - \\
\hline- & - & - \\
\hline - & - & - \\
\hline- & - & - \\
\hline- & - & - \\
\hline- & - & - \\
\hline- & - & - \\
\hline- & - & - \\
\hline+ & + & + \\
\hline- & - & - \\
\hline- & - & - \\
\hline- & - & - \\
\hline- & - & - \\
\hline- & - & - \\
\hline- & + & + \\
\hline- & - & - \\
\hline- & - & - \\
\hline- & - & - \\
\hline- & - & - \\
\hline- & - & - \\
\hline- & - & - \\
\hline+ & + & + \\
\hline- & - & - \\
\hline- & - & - \\
\hline- & - & - \\
\hline- & - & - \\
\hline- & - & - \\
\hline+ & + & + \\
\hline+ & + & + \\
\hline+ & + & + \\
\hline- & - & + \\
\hline- & + & + \\
\hline+ & + & + \\
\hline- & - & - \\
\hline
\end{tabular}


TABLE II. (continued)

\begin{tabular}{lccc}
\hline \multicolumn{1}{c}{ Test organisms } & \multicolumn{3}{c}{ Growth } \\
\cline { 2 - 4 } & 4 & 7 & 12 (days) \\
\cline { 2 - 4 } Curvularia geniculata IAM 5019 & - & + & + \\
Fusarium lini IAM 5008 & + & + & + \\
Fusarium moniliforme IFO 6349 & + & + & + \\
Fusarium oxysporum IAM 5051 & + & + & - \\
Fusarium roseum IFO 5421 & - & + & + \\
Gibberella fujikuroi IAM 8048 & + & + & + \\
Helminthosporium sativum IAM 5023 & + & - & + \\
Macrosporium bataticola IAM 5014 & - & + & - \\
Monilia candida M-13* & + & - & + \\
Ophiobolus graminis O-4* & - & + & + \\
Pyricularia oryzae IAM 5016 & + & + & + \\
Sclerotium oryzae S-3* & - & + & + \\
\hline
\end{tabular}

* Strain from the culture collection of the National Institute of Agricultural Science, Ministry of Agriculture, Forestry and Fisheries (NIAS).

Table III. Grouping of the Microorganisms Isolated on High AlKaline Media

The antimicrobial activities were measured by the pulp-disk method, and showed an inhibition zone diameter of over $12 \mathrm{~mm}$.

\begin{tabular}{lcccccc}
\hline & \multicolumn{1}{c}{$\begin{array}{c}\text { Strains with } \\
\text { Isolated strains }\end{array}$} & $\begin{array}{c}\text { antibiotic } \\
\text { activities }\end{array}$ & I & Types* of antibiotic activities \\
\cline { 4 - 7 } & 1511 & 148 & 78 & 8 & III & IV \\
\hline Fungi & 1206 & 151 & 73 & 20 & 24 & 38 \\
Streptomycetes & 283 & 36 & 31 & 0 & 44 & 14 \\
Bacteria & & & & 0 & 5 \\
\hline
\end{tabular}

* The types of antibiotic activities were as follows: Type I, active for Gram positive bacteria; Type II, active for Gram positive and negative bacteria; Type III, active for fungi; Type IV, active for gram positive bacteria and fungi.

acetate. The solvent layer was concentrated in vacuo to an oily material, which was subjected to silica gel (Wako gel C-200; Wako Pure Chemical Industries, Ltd.) column chromatography using a mixed solvent of chloroform and methanol $(20: 1, \mathrm{v} / \mathrm{v})$. The active fractions were concentrated and purified by preparative silica gel (Silica Gel $60 \mathrm{~F}_{254}$; E. Merck, Darmstadt) thin-layer chromatography. Finally the active substance was subjected to Sephadex LH-20 (Sephadex LH-20; Pharmacia Fine Chemicals AB, Uppsala, Sweden) column chromatography with elution with methanol and a pure substance $(5.3 \mathrm{mg}$ ) was obtained. Physicochemical properties of this substance were compared with those of authentic antimycin A (Sigma Chemical Co., Ltd.) and substance No. 1543 was completely identified as antimycin A.

The antibiotic derived from an alkalineresistant fungal strain, No. 401, was identified as helvolic acid by comparison with an authentic sample. Details of the isolation and identification of helvolic acid were described in the patent by the authers. ${ }^{11)}$

Taxonomical studies on fungal strain No. 1907

Fungal strain No. 1907 was isolated from a soil sample collected in Koishikawa Botanical Garden, Tokyo, Japan, on the high alkaline medium B.

Colonies on malt agar grew rather rapidly, 


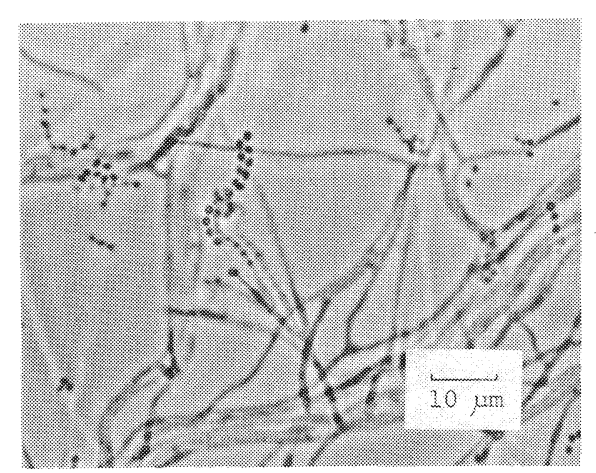

FIG. 1. Microphotograph of Strain No. 1907 after Slide Culture.

attaining a diameter of $38 \sim 40 \mathrm{~mm}$ within 10 days at $26.5^{\circ} \mathrm{C}$, consisting of a basal felt with a floccose overgrowth of aerial mycelium; at first white, but when sporulating changed to pale red-purple. The reverse was sometimes uncolored, but usually yellow to brown. Exudate was absent. Odour was indistinct. Vegetative hyphae were smooth-walled, hyaline, $2.5 \sim 4.0 \mu \mathrm{m}$ wide. Conidiophores arose from submerged hyphae, consisting of verticillate branches with whorls of two to four phialides. Phialides were $7.5 \sim 12.5 \times 2.2 \sim 2.5 \mu \mathrm{m}$ in size, consisting of a swollen basal part, tapering into a thin distinct neck, about $1 \mu \mathrm{m}$ wide. Conidia were in divergent chains, ellipsoidal to fusiform, smooth-walled to slightly roughened, hyaline, purple in mass, $2.3 \sim 2.5 \times$ $2.0 \sim 2.3 \mu \mathrm{m}$. Chlamydospores were absent. A microphotograph of strain No. 1907 after slide culture is shown in Fig. 1.

Physiological properties of strain No. 1907 were as follows; the growth temperature range was $9.0 \sim 35.2^{\circ} \mathrm{C}$ and the strain grew well at $22.5 \sim 33.6^{\circ} \mathrm{C}$. The growth $\mathrm{pH}$ range was $\mathrm{pH}$ $2.5 \sim 11.0$ and the strain grew well in alkaline conditions, $\mathrm{pH} 7.5 \sim 9.0$.

The description of Paecilomyces lilacinus by Samson $^{15)}$ agreed well with the characteristics of strain No. 1907. Paecilomyces lilacinus ATCC 10114 (type culture) and P. lilacinus IAM 7002 were compared with strain No. 1907. In respect of the growth rate of colonies, the color of colonies and the morphological

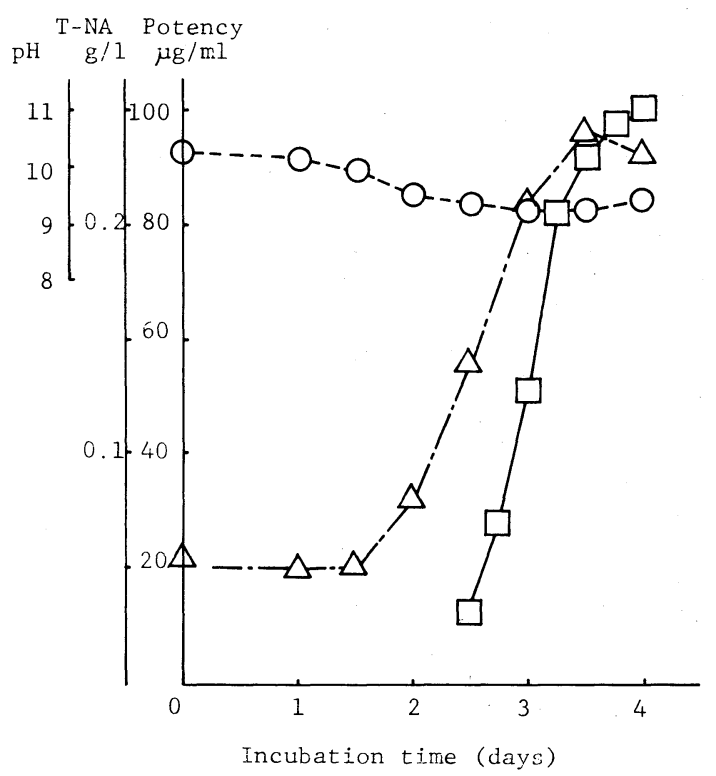

FIG. 2. Time Course of Fermentation of Antibiotic No. 1907.

Fungal strain No. 1907 was cultured in a 20-liter jar fermentor containing 10 liters of Medium $\mathrm{C}$ with agitation at $250 \mathrm{rpm}$ and aeration of 5 liters per min at $26.5^{\circ} \mathrm{C}$. $-\mathrm{O}-, \mathrm{pH} ;-\triangle-$, total nucleic acid content (T-NA); $-\square-$, potency by bioassay.

characteristics of phialides and conidia, strain No. 1907 was midway between Paecilomyces lilacinus ATCC 10114 and P. lilacinus IAM 7002. The productivity of antibiotics by these reference strains was examined, and both strains showed no antimicrobial activities. Based on these observations including the alkalophilic growth, strain No. 1907 should be a physiological variant of Paecilomyces lilacinus.

Fermentation of antibiotics of strain No. 1907

A seed culture of fungal strain No. 1907 was carried out in a 500-ml Sakaguchi flask containing $100 \mathrm{ml}$ of medium $\mathrm{D}(\mathrm{pH} \mathrm{9.6).} \mathrm{The}$ composition of medium $\mathrm{D}$ is shown in Table $\mathrm{I}$. The inoculated flask was cultured for 2 days at $28^{\circ} \mathrm{C}$ on a reciprocal shaker. Three hundred $\mathrm{ml}$ of the seed culture prepared as described above was inoculated into a 20-liter jar fermentor containing 10 liters of medium C (Table I). Cultivation was carried out with agitation at 
$250 \mathrm{rpm}$ and aeration of 5 liters per minute at $26.5^{\circ} \mathrm{C}$. A typical time course of fermentation of strain No. 1907 is illustrated in Fig. 2.

The $\mathrm{pH}$ was maintained between 10.25 and 9.0 during the fermentation process. The production reached $100 \mu \mathrm{g}$ per $\mathrm{ml}$ at 4 days incubation. The cells after 4 days incubation showed almost yeast-like morphology. When strain No. 1907 was cultured at neutral pH, the cells showed filamentous growth but no antimicrobial activities were detected in the broth. The production of antibiotics, therefore, depended upon the alkaline $\mathrm{pH}$ of the broth.

\section{Recovery and purification of antibiotics of strain} No. 1907

Strain No. 1907 was found to produce a group of homologue antibiotics, I to VIII, among which II was a major component, and several unidentified minor products were also produced.

The procedures for isolation and purification of antibiotics Nos. 1907-II and VIII are

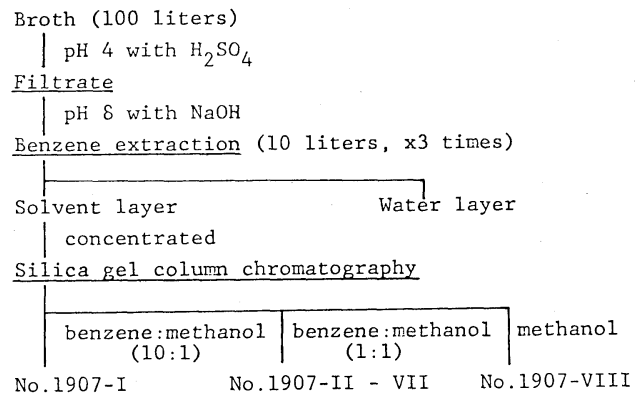

FIG. 3. Recovery and Purification Process of Antibiotics No. 1907.

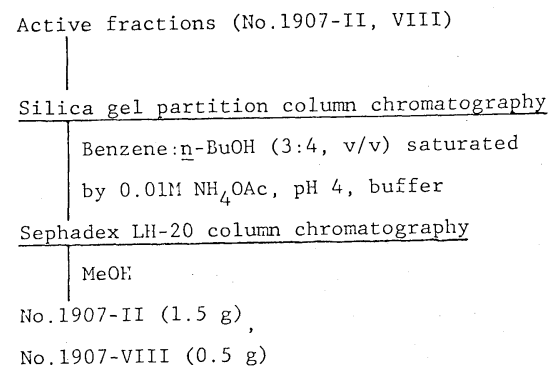

FIG. 4. Isolation Process of Antibiotics No. 1907-II and No. 1907-VIII. schematically presented in Figs. 3 and 4.

The fermentation broth (100 liters) adjusted to $\mathrm{pH} 4$ with sulfuric acid was filtered using a filter aid (Topco Perlite No. 34, Toko Perlite Co., Ltd., Japan). The clear filtrate was adjusted to $\mathrm{pH} 8$ with sodium hydroxide and extracted three times with 20 liters of benzene. The solvent layer was concentrated to an oily material in vacuo and subjected to silica gel column chromatography. Three fractions, each containing mainly homologue $\mathrm{I}$, a mixture of II to VII, and VIII, were eluted successively with benzene-methanol $(10: 1, \mathrm{v} / \mathrm{v})$, benzene-methanol $(1: 1, \mathrm{v} / \mathrm{v})$ and methanol, respectively. Each active fraction was concentrated and dried in vacuo. A silica gel thin-layer chromatogram of each fraction is shown in Fig. 5. Antibiotics Nos. 1907-II and VIII were further purified by silica gel parti-

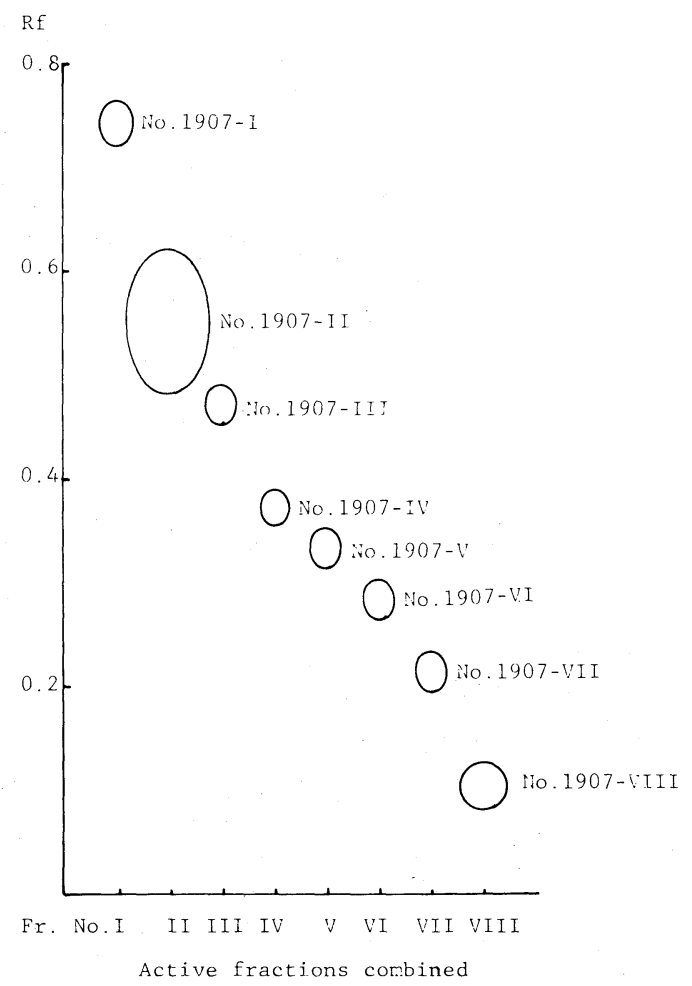

FIG. 5. Diagrammatic Thin-Layer Chromatogram of Active Fractions on Silica Gel Column Chromatography. Plate, pre-coated Silica Gel 60 F-254 (E. Merck); detection, UV-light at $254 \mathrm{~nm}$; solvent system, benzene$\mathrm{MeOH}(1: 1)$. 


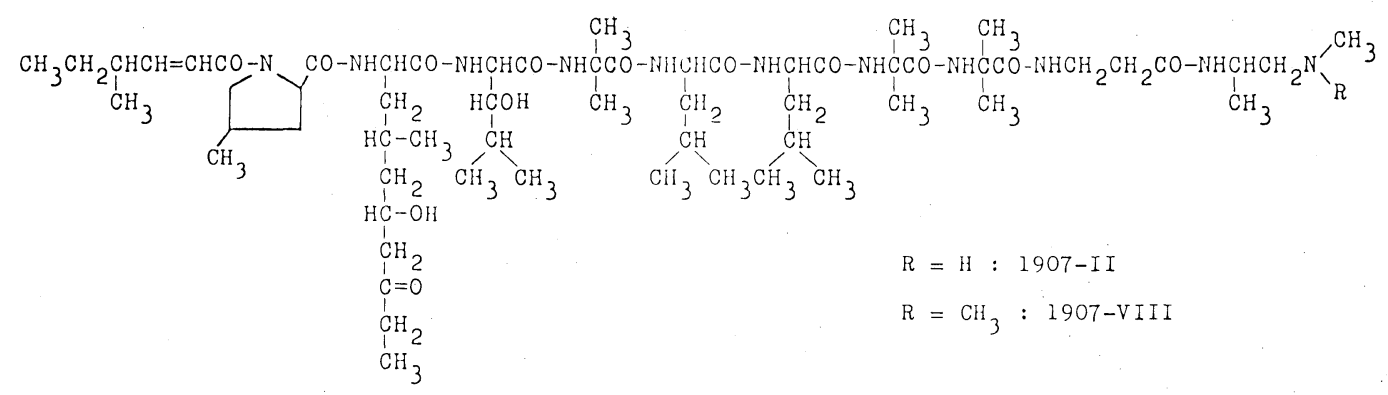

FIG. 6. Structures of Antibiotics of Strain No. 1907.

tion column chromatography, respectively. Both antibiotics were clearly separated from other minor components by the elution system described in Materials and Methods. Finally, fractions of Nos. 1907-II and VIII were subjected to Sephadex LH-20 column chromatography for deionization and pure colorless powders of Nos. 1907-II (1.5 g) and VIII $(500 \mathrm{mg})$ were obtained. The purity was confirmed by the single peak on HPLC analysis.

Figure 6 shows the structures of Nos. 1907II and VIII. They had the same structure except for the amine moiety at the C-terminal of the peptide. These peptide antibiotics had unique structures which contained a new amino acid, 2-amino-4-methyl-6-hydroxy-8oxodecanoic acid. ${ }^{7,16)}$ The same antibiotic as No. 1907-VIII was independently reported from Paecilomyces lilacinus (Thom) Samson ${ }^{17)}$ and P. lilacinus A-267. ${ }^{18)}$ Antibiotic I. C. I. No. $13959^{19)}$ seemed to be an analogue of antibiotic No. 1907 since its amino acid components were almost the same except for the new amino acid. Also trichopolyns produced by Trichoderma polysporum ${ }^{20)}$ have a similar structural feature with several amino acid substitutions.

The unidentified minor products of antibiotics of strain No. 1907 will be isolated and reported in the near future.

Acknowledgments. The authors express their deep gratitude to Professor S. Okuda of the University of Tokyo for supplying them with the authentic sample of helvolic acid and to Dr. K. Kouno and Mr. T. Kumamoto of Sanraku-Ocean Co., Ltd. for valuable advice on taxonomical studies. They also wish to thank Dr. K. Aizawa of this Department for the EI-MS analysis and to Sanraku-Ocean Co., Ltd. for the large scale preparation.

\section{REFERENCES}

1) K. Arima, H. Imanaka, M. Kousaka, A. Fukuda and G. Tamura, J. Antibiot., 18, 201 (1965).

2) K. Ogata, N. Yoshida, M. Ohsugi and Y. Tani, Agric. Biol. Chem., 35, 79 (1971).

3) T. Okazaki, T. Kitahara and Y. Okami, J. Antibiot., 28, 176 (1975).

4) Y. Okami, T. Okazaki, T. Kitahara and H. Umezawa, J. Antibiot., 29, 1019 (1976).

5) K. Horikoshi, Agric. Biol. Chem., 35, 1407 (1971).

6) K. Horikoshi and T. Akiba, "Alkalophilic Microorganisms," Japan Scientific Press, Tokyo, 1982.

7) M. Sato, T. Beppu and K. Arima, Agric. Biol. Chem., 44, 3037 (1980).

8) E. Volkin and W. E. Cohn, "Methods of Biochemical Analysis,” Vol. I, 1954, p. 287.

9) K. Nakayama, F. Okamoto and Y. Harada, J. Antibiot., 9, 63 (1956).

10) S. Okuda, S. Iwasaki, K. Tsuda, Y. Sano, T. Hata, S. Udagawa, Y. Nakayama and H. Yamaguchi, Chem. Pharm. Bull., 12, 121 (1964).

11) M. Sato, T. Beppu and K. Arima, Jpn. Patent, 082276 (1976).

12) S. A. Waksman, E. S. Horning and E. L. Spencer, Science, 96, 202 (1942).

13) K. Tsuda, S. Okuda, T. Hata, Y. Sano, Y. Nakayama, A. Matsuda, K. Tawara and $H$. Yamaguchi, Jpn. Patent, 6369 (1965).

14) T. Hata, Y. Sano and A. Matsumae, Jpn. Patent, 12669 (1966).

15) R. A. Samson, "Paecilomyces and Some Allied Hyphomycetes," Studies in Mycology, No. 6, 1974, p. 58.

16) A. Isogai, A. Suzuki, S. Higashikawa, S. Kuyama and S. Tamura, Agric. Biol. Chem., 44, 3029 (1980).

17) A. Isogai, A. Suzuki, S. Higashikawa, S. Kuyama 
and S. Tamura, Agric. Biol. Chem., 44, 3033 (1980).

18) Y. Mori, M. Tsuboi, M. Suzuki, K. Fukushima and

T. Arai, J. Chem. Soc., Chem. Commun., 94 (1982).

19) G. W. Kenner and R. C. Sheppard, Nature, 181, 48
(1958).

20) T. Fujita, Y. Takaishi and A. Okamura, J. Chem. Soc., Chem. Commun., 585 (1981). 